\title{
Pinto Durán, Astrid Maribel (2013), Guerreros de luz. Enseñanzas de don Lauro para una RED Cósmica de ESPIRItUALIDAD. MÉxico: CONACULTA.
}

\author{
Anna María Fernández-Poncela
}

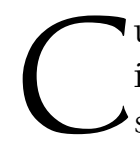

uando varias revistas científicas internacionales inician el camino del reconocimiento de los supuestos descubrimientos que tienen que ver con el mundo cuántico de los últimos años, y que en realidad son los antiguos conocimientos de la mística de siempre y de siglos atrás, aparece también una excelente obra titulada Guerreros de luz. Enseñanzas de don Lauro para una red cósmica de espiritualidad. La autora, Astrid Maribel Pinto Durán, doctora de la Universidad de Ciencias y Artes de Chiapas, docente e investigadora de nuestra realidad social, nos presenta una obra desde una mirada que hay quien desacredita o sobre la que ironiza desde la atalaya científica, el dogma político o la ignorancia sobre la vida.

Entre tanta liquidez, riesgo, vacío, hiperrealidad o hiperconsumo, por citar sólo algunos de los conceptos de moda del análisis social en el mundo actual, todos ellos encauzados hacia la desesperanza, llega a la luz — nunca mejor dicho - un trabajo en el sentido opuesto: la esperanza, lo cual se agradece sobre todo para quienes por ella apuestan, y también seguramente para quienes están cómodamente instalados en el discurso del pesimismo, pues este libro es una oportunidad para cambiar de aires aunque sea por un rato y para romper algunas viejas estructuras de la mente y el estado de ánimo.

Bajo tantas distopías cinematográficas y terrorismo mediático, envueltos en discursos políticos vacíos, redundantes o cínicos, es bueno leer: "El progreso, la razón, no nos han hecho, finalmente, tan felices: hemos conducido al planeta a un estado de contingencia y algunos hasta hemos llegado a creer que no existen otros sueños realizables, otras salidas sino políticas, otras ilusiones capaces de dinamizar la realidad hipostasiada" (p. 204). Este libro es una invitación a un reencuentro con nosotros mismos, con el cuerpo, la energía, la imaginación, la tradición, la naturaleza, la justicia, la libertad y, repito, con la esperanza.

Me gusta leer y escuchar palabras como imaginarios, utopías, mitos, sueños, metáforas, espiritualidad y corazón. Todos estos son conceptos mágicos, como mágicos son don Lauro, la ciudad de San Cristóbal de Las Casas y México, y como mágica es la vida. Mucho me gustaría ahondar sobre estos conceptos, los debates y los autores y autoras que han abordado estos temas y el enfoque y uso que Pinto Durán les da, pero hay 
cosas más importantes que reclaman mi atención en este libro. Como digo a mis alumnos -y me digo a mí misma-, la vida es más importante que la investigación y la academia.

El libro remite a una revolución de luz y de ideas, a un cambio de conciencia, a un pueblo que despierta y a un gran cambio espiritual y cultural en el que pensamientos y emociones se limpian para que las transformaciones sociales de justicia y dignidad y la sobrevivencia ecológica, tengan sentido, se arraiguen y permanezcan. De la cultura no nos podemos salir, dice Butler. Yo a veces añado que de las emociones tampoco, pero iy si sí nos podemos salir? Sí podemos despertary sí podemos llegar a ser lo que realmente somos, personas, como dice Rogers respecto a su terapia, o como afirma don Lauro: mayas galácticos.

Este libro, más allá del personaje don Lauro y sus circunstancias, y de los guerreros de luz y sus prácticas, es un digno ejemplo de descolonización de la ciencia y de la conciencia. Esto acontece cuando una antropóloga o cientista social - poco importarespeta al objeto-sujeto de investigación y, lejos de la descripción folclórica y la explicación ingenua o ignorante, cuando no irónica, se integra y lo integra. Los libros plasman y difunden conocimiento - nunca mejor dicho-. Este libro lo despliega y regala. Puedes creerlo o no, compartirlo o no, pero ese no es el fin. La meta es sembrar aperturas en la mente e inquietudes en el corazón, espacios para la confianza y la esperanza, lo contrario del miedo, los aliados del amor.

Eso sí, el cambio duele, duele mucho, en el cuerpo y en el alma, porque es la purificación que necesitamos para destruir creencias, desestructurar mentes, desbloquear emociones y trocar hábitos; para romper con la jaula que nos hemos construido y con el sistema, que nos envuelve entre poder y seducción dentro de la pesadilla que estamos cocreando y alimentando. Si tú cambias, tu mundo cambia, porque el cambio empieza desde adentro, por uno o una misma, al romper estructuras, reírse de la vida y atreverse a experimentar. Para salir de la "matrix", primero hay que romper la propia prisión de la mente, como diría Prem Dayal, y luego la cárcel de la luna, según Velasco Piña, y quizás los verdaderos poderes económicos y políticos terrenos, añadiría. También hay que saber que el camino está sembrado de dudas, las tuyas, las mías, las nuestras. La cúspide no se sabe dónde está, pero cuando hace su presencia el viento, lo importante no es sentir el viento ni saber que eres el viento, lo importante es ser el viento. En un momento en que estamos aprendiendo a asumir que si sembramos paz eso vamos a cosechar, y que si emitimos violencia recibiremos violencia, bien vale la pena echarse un clavado a este libro que apuesta por lo primero, que navega entre interrogantes y llega al puerto de la conciencia, o quizá sería mejor o más correcto decir que permanece navegando en un mar en calma y eterno, como es el universo.

En cuanto a temática, esta obra es de vanguardia por lo anteriormente mencionado. Y en cuanto a método y forma, también, ya que se encuentra entre las investigaciones situadas y encarnadas (Harding, Haraway) según las nuevas metodologías, lo que parece más que claro desde la página 33: "mi antipatía se convirtió en un genuino interés académico", "la empatía queda en este caso como un secreto vergonzoso" (p. 34), "Fui registrando los cambios en mi propio ser [...] Mi mirada empática, sin embargo, ha implicado una disyuntiva de lealtad como practicante de las enseñanzas de don Lauro y como antropóloga" (p. 39). Nadie es más fuerte que quien desnuda su vulnerabilidad, ni más objetiva que quien confiesa su subjetividad.

\footnotetext{
Puedo observar en mí misma cómo este encuentro con don Lauro había desordenado de manera violenta mi manera de pensar la vida: mi racionalidad fue tocada sensiblemente y desde aquel momento tuve que admitir que el mundo podía ser pensado y vivido de otra manera. Una idea a la cual había tenido acceso por la vía académica, pero que se había quedado a nivel de pensamiento (p. 39).
}

Con esta frase, Astrid muestra su sabiduría, pero mucho más que eso, nos modela con su ejemplo un camino a seguir, el camino espiritual, sin por ello despegarnos de la tierra y la justicia social. Además nos descubre la 
necesidad no sólo de abrir las ciencias sociales, como diría Wallerstein, ni de tener la sensibilidad racional de Maffesoli o de desechar la racionalización según Morin, sino más que eso: la necesidad de revolucionar los paradigmas, como Mignolo o De Sousa Santos o Quijano o Bhabha, pero, más todavía, de investigar con el corazón.

Investigar algo nuevo, desde una fresca mirada despojada de la máscara científica o de lo políticamente correcto y confesando vulnerabilidades, requiere de una sabiduría entremezclada con valentía y envuelta de conciencia, de la que la autora da muestras sobradas en este libro. Astrid Pinto pone en sus manos, amigo lector, una obra que puede leer cual novela de ciencia ficción, estudio de caso antropológico o reflexión filosófica, usted elige. Como también puede elegir - ya dijo Sartre que estamos condenados a ello- afilar la descalificadora crítica académica, sentarse a meditar o empezar la búsqueda de su camino espiritual. También es opcional utilizar las páginas de este libro para encender un fuego. Piense primero en los árboles sacrificados, en las horas robadas al sueño para escribirlo, en la contaminación atmosférica $y$, en último término, por lo menos en que la llama queme y se lleve su propio enredo mental y emocional. También pudiera ser que el libro sea cual semilla sembrada en lo más profundo y oscuro de su inconsciente, que encuentre tierra fértil en su corazón y que broten dudas en su cerebro, se tambaleen creencias, se resquebrajen razones y florezcan posibilidades en su ser.

Se trata de todo un trabajo de descolonizar — ahora que está de moda este enfoque social — no sólo las teorías y las prácticas, también tu interior y la inconsciencia planetaria. Esta es una obra para mover y conmover. Si te ha enojado, lo consigue; si te ha emocionado, lo consigue; si la odias, lo consigue; si la amas, lo consigue; si te atemoriza, lo consigue, y si te ha dejado bailando en el espacio, también lo consigue. Como me dijo una vez don Lauro: "si tus alumnos se ríen y hacen relajo cuando los invitas a respirar, ya lo hiciste, ya rompiste los esquemas". Eso es lo que este libro logra sin bajar el nivel académico que nos exigen en la universidad: llevarte a los espacios ignotos de tu sombra, iluminar tu sendero hacia el universo.
La obra finaliza con la respuesta a una pregunta:

- iHas tenido algún tipo de problema en el medio académico por tu práctica espiritual?

-Bueno, lo que pasa es que este tipo de simpatías está mal legitimada. Sí, porque en la academia yo creo que nos quedó el resabio del marxismo: todo lo que huele a religión y espiritualidad y esas cosas se interpreta como el opio del pueblo, como manipulación ideológica (p. 250).

Una participante del grupo de don Lauro responde así a la pregunta de la investigadora. Seguramente es también lo que la autora siente y yo comparto. Seguramente esta forma de acabar no es inocente, es una invitación a la reflexión, una exhortación a ver cómo seguimos con paradigmas obsoletos, cómo la ciencia se dogmatizó, cómo no sirve a la sociedad, cómo esclaviza cuerpos e intoxica mentes además de desquiciar emociones, y cómo nos atonta en medio de tanta información y tecnología y tan poca lógica y corazón. Es hora de crear una nueva ciencia porque no hay una única verdad, y de que desaparezca el rollo o "choro" mental para pensar con el cerebro del corazón, porque existen muchos caminos. Lo importante es caminar.

Y con esa empatía inconfesable, como ya se dijo, confieso que leí gustosa y feliz el libro de Astrid, desde el corazón, no desde la mente, desde el amor, no desde el miedo, desde la esperanza, no desde la desesperanza, sumidos como estamos en el sueño de la "matrix", desconectadas de nosotras mismas, de la Madre Tierra, del hogar universal y de la fuente de la vida. Y es que "El despertar de la conciencia significa, entre otras cosas, admitir que estamos enfermos. Enfermos por la realidad asimilada como la única posibilidad de realidad y que además no está fuera de nosotros: la realidad, tal como la hemos aprendido, la llevamos como improntas en nuestro cuerpo" (p. 68). Como dice una maestra a Astrid: "Esta es una escuela de vida, de regresar a nuestra naturaleza, de regresar a lo que realmente somos. Es una escuela que nos enseña la sabiduría, la felicidad, lo más hermoso que existe está en la simplicidad de las cosas" (p. 69), en amar lo que es, según Katie, en hacer lo que la 
vida quiere, no lo que nosotras y nosotros queremos, nos recuerda Frankl, en crear la nueva tierra, según Tolle.

Cuando nos estábamos preguntando con Watzlawick qué es la realidad, llegó don Lauro y nos respondió:

La realidad no es sólo lo que podemos ver o tocar. Hay cosas que podemos sentir y vivir y no las podemos ver. Nuestra idea de realidad está atrapada en nuestra visión del tiempo y el espacio lineal. Lo que hicimos y vivimos ahora no corresponde a esa realidad. Nosotros hemos viajado, nos hemos desplazado por túneles del tiempo y hemos llegado a otros espacios, a otras dimensiones (p. 88).

Y no es de extrañar que el científico Garnier esté interesado en su teoría del desdoblamiento del tiempo y que ya se reconozcan sus descubrimientos de hace más de dos décadas, aunque los mayas y teotihuacanos o griegos varios siglos antes ya lo sabían. Lo que la física cuántica parece estar descubriendo en los últimos años o durante el pasado siglo, varias generaciones anteriores a la nuestra en el planeta tierra lo conocían y lo vivían sin necesidad del beneplácito y la bendición científica. ¿Quieres seguir estando al servicio del dogma científico? ¿Deseas seguir siendo esclavo de tus pensamientos y de los pensamientos de los otros? ¿Vas a continuar con el personaje teatral que representas?

"La producción imaginaria de un mundo distinto: la imaginación utópica" (p. 25). Eso que la autora dice que quiere el grupo que estudia es, creo, lo que muchas y muchos deseamos. Por todo ello, no puedo más que ser coherente y agradecer de todo corazón este trabajo, pionero en los temas que aborda, de vanguardia en nuevos enfoques epistemológicos y metodológicos $y$, sobre todo, un ejemplo a seguir por quienes compartimos desde el corazón el camino del cual Astrid tan sabia y valientemente nos lleva de la mano a lo largo de estas 252 páginas de luz, abandonando el corsé académico y fundiéndose con lo importante: la vida.

Finalmente, reprimiendo todo lo que una quiere expresar acerca de esta magnífica obra académica, de difusión, y sobre todo de existencia, sólo me queda confesar que soy una estudiante más de la vida, agradecer desde el corazón los aportes de Astrid, y despedirme con la clara conciencia de que somos más de lo que nos han dicho y creemos ser. Tenemos que liberarnos de nosotros mismos y del sistema para ver lo invisible, escuchar lo inaudible, leer la naturaleza y seguir la intuición.

Más que imaginarios utópicos, todo esto son realidades posibles - como anuncia el título de esta reseña- y están ahí, a la vuelta de la esquina; podemos ignorarlas, pero ellas seguirán existiendo como una mancha de conciencia se extiende sobre la Madre Tierra, que es sagrada. Es tiempo de compartir lo académicamente incorrecto, de romper estructuras, de creer y crear y de lanzarnos a la hoguera sabiendo que el fuego es nuestro aliado y que limpia lo que nosotros ensuciamos, nuestros egos, dramas, basura mental y emocional, desconexión, manipulación. Es tiempo de enloquecer si la cordura es ser esclavos de un celular, prisioneras de un espejo, parte de una sociedad en la que desaparecen personas y colectivos pasan hambre. Rifkin nos habla de la evolución de la empatía, Margalit de la necesidad de una sociedad decente y don Lauro afirma: "si tú encuentras tu paz, ya salvaste al mundo", "dale alegría a tu espíritu y deja que él se manifieste", "hay que buscar y encontrar la conexión", "la única misión del ser humano es ser feliz". Cada quien sabrá qué pensar, sentir y hacer con esto.

\section{Esperanzados en las transformación que se pudiera alcanzar realizando un trabajo con la energía a nivel individual y colectivo, los trabajadores de la luz coinciden en que hay que levantar la frecuencia de la humanidad, sacar a ésta del pesimismo en el que se ha hundido, restituirle su sacralidad para sanar el planeta y nuestra especie, generar un movimiento de transformación desde su interior, ampliar la conciencia de sus espejismos creados por el consumo, nutrirla de esperanza, de utopía (p. 180).}

Bienvenida esta obra de erudición milenaria y galáctica que aterriza en la práctica de la vida cotidiana, rompiendo los deberes académicos, la intelectualidad 
entumecida, el cientifismo trasnochado, la heterodoxia ideológica, el consumismo sacralizado y la virtualización de la existencia. Bienvenida porque dinamita la presa artificial de la academia para ahogar el asfixiante cientificismo y regar las dormidas consciencias en momentos de sequía.

Creer es crear, dice Pando; crea y créetelo, afirma don Lauro. iSerá este libro producto de imaginación utópica o la neta del planeta? Hoy la locura o la iluminación no siempre conducen a la hoguera como en otra época; sin embargo, se reconocen como verdad varios años después; esperemos llegar a tiempo. De momento ya tenemos pistas y podemos seguir huellas, si no es por conciencia, por conveniencia, porque, como dice el dicho, iquieres tener la razón o ser feliz? Conviene pararse un rato a sentir, a reflexionar un poco en torno a los aportes de esta maravillosa inyección de buena vibra, vacuna para las vacunas virales que el sistema nos tiene destinadas. Este es el libro de Astrid Pinto.

Tú eres yo y yo soy tú. Tú eras, serás y eres. Me despido con el saludo de algunos grupos mayas: “¿Cómo está tu corazón?" 